Bangladesh J. Bot. 47(4): 937-943, 2018 (December)

\title{
GENETIC VARIATION IN HYDRANGEA MACROPHYLLA (THUNB.) SER. IN RUSSIA BASED ON SIMPLE SEQUENCE REPEAT MARKERS
}

\author{
Natalia Sukhikh, Valentina Malyarovskaya ${ }^{1}$, Anastasiya Kamionskaya, \\ Lidia Samarina ${ }^{*}{ }^{*}$ and Svetlana VinOgRadova ${ }^{2}$ \\ Institute of Bioengineering, Research Centre of Biotechnology of the Russian Academy of \\ Sciences; 33, bld. 2 Leninsky Ave., Moscow, 119071, Russia
}

Keywords: Hydrangea macrophylla, Molecular markers, SSR-markers, DNA polymorphism

\begin{abstract}
Genetic diversity and genetic relationships among 39 accessions of Hydrangea macrophylla (Thunb.) Ser. were analyzed using 38 previously developed simple sequence repeat markers (SSRs). A total of 38 polymorphic primers representing 166 bands with an average of 4.53 polymorphic bands per primer were selected. The number of alleles detected per locus ranged from two to eight with a total of 163 alleles amplified. The size of the amplified fragments ranged from 70 to180 base pairs. The effective multiallelic markers with high level of heterozygosity (more than 0.7) and effective number of alleles (more than 3.5) were identified. In this study nine SSR markers showed clear polymorphisms. The dendrogram grouped all hybrids in three major clusters, and two of these clusters included only mophead cultivars. The lacecap cultivars clustered more closely to each other. The results of this research could be used in breeding programs of H. macrophylla.
\end{abstract}

\section{Introduction}

The genus Hydrangea is represented by nearly 23 species (McClintock 1957). It has a wide distribution in tropical regions of southern and eastern Asia (China, Japan, Korea, the Himalayas, and Indonesia) and the America. The first species of Hydrangea was introduced in Russia in the second half of the $19^{\text {th }}$ century. Nowadays seven species of Hydrangea grow in Russia, including H. macrophylla (Thunb.) Ser., H. arborescens L., H. petiolaris Sieb. et Zucc, H. paniculata Sieb, $H$. radiata Walt., H. quercifolia Bartr., and H. serrata (Thunb. ex Murray) Ser. (Polyakova and Murzabulatova 2014). Two of these species, $H$. petiolaris and $H$. paniculata grow wildly in the south of Russia. Hydrangea macrophylla, H. arborescens and H. paniculata are cultivated as ornamentals. The most popular garden and pot shrub is $H$. macrophylla.

One of the oldest Russian H. macrophylla collections was in the Black Sea coast region at the Subtropical Botanical Garden. It represents cultivars introduced during 1930 - 1960 and cultivars developed at the end of the $20^{\text {th }}$ century. Some were introduced from The Tsytsin Main Moscow Botanical Garden of Academy of Sciences (Moscow, Russia) and The Komarov Botanical Institute of the Russian Academy of Sciences (Saint Petersburg, Russia). Additionally, there are several cultivars introduced from Japan to Europe in the 1800s (H. macrophylla 'Joseph Banks', H. macrophylla 'Jogosaki') or developed in Europe during the first half of the $20^{\text {th }}$ century (H. macrophylla 'Altona', group of Mariesii cultivars). Some of the cultivars seem to be labeled incorrectly because they have a different phenotype (Malyarovskaya 2015). Sepal color of $H$. macrophylla cultivars can vary depending on $\mathrm{pH}$ of the soil, making cultivar identification difficult and inaccurate (Kardos et al. 2009). Compared to morphological characteristics, molecular markers provide more reliable information about cultivar specificity and relationships.

\footnotetext{
*Author for correspondence: <samarinalidia@gmail.com>, ${ }^{1}$ Federal State Budgetary Scientific Institution «Russian Research Institute of Floriculture and Subtropical Crops», Sochi, 354000, Russia. ${ }^{2}$ Institute of Bioengineering, Research Centre of Biotechnology of the Russian Academy of Sciences; 33, bld. 2 Leninsky Ave., Moscow, 119071, Russia
} 
Several types of molecular markers have been used to study hydrangeas including random amplified polymorphic DNA (RAPD), amplified fragment length polymorphisms (AFLP), inter simple sequence repeats (ISSR) and microsatellites or simple sequence repeats (SSR). Recently RAPD markers were used to determine genetic diversity and relationships within and between Hydrangea species (Uemachi et al. 2014), to identify interspecific hybrids (Reed et al. 2005), to estimate remontant (reblooming) cultivars (Lindstrom et al. 2003), and to identify Hydrangeaceae accessions of wild origin (Joung et al. 2010). Lee and Hyun (2007) used AFLP markers for fingerprinting of $H$. macrophylla cultivars. Putative hybrids of $H$. paniculata and $H$. quercifolia were confirmed through AFLP (Van Huylenbroeck 2004). Additionally, ISSR markers were used in other research for identification of botanical varieties and cultivars from nine Hydrangea species (Mortreau 2003).

The technical efficiency and multiplex potential of SSRs markers make them suitable for genetic analysis and marker-assisted selection (MAS). Main uses of SSR markers for hydrangeas include: identification of the relationship between Hydrangea species (Rinehart et al. 2005), estimation of genetic distances between H. macrophylla cultivars (Reed and Rinehart 2007), verification of interspecific hybrids between $H$. macrophylla and $H$. angustipetala (Kardos et al. 2009), and intergeneric hybrids between Dichroa febrifuga Lour. and H. macrophylla (Jones et al. 2006). Several recent studies clarified the taxonomy of H. macrophylla, assessed genetic diversity of the species, and helped breeders develop new or improved cultivars (Adkins and Dirr 2003, Cerbah et al. 2001, Kardos et al. 2009). There are 39 and 26 SSR loci that were developed for H. macrophylla (Reed and Rinehart 2007) and H. paniculata (Reed and Rinehart 2009) respectively. These markers could be used for genetic diversity analysis between different cultivars, for verifying interspecific hybrids and for developing MAS programs. The objective of the present study was to estimate SSR markers for evaluation of genetic relationships within H. macrophylla cultivars from the Subtropical Botanical Garden.

\section{Materials and Methods}

In present study plant materials consisting of 39 accessions of Hydrangea macrophylla (Table 1) from the Subtropical Botanical Garden collection on the Black Sea coast of Russia were used. The origin of some cultivars is unknown. Total genomic DNA was extracted from leaves by potassium acetate extraction method (Edwards et. al. 1991) with an additional phenol-chloroform purification. The DNA concentration and quality were measured by a NanoDrop 2000 spectrophotometer and $1 \%$ agarose gel electrophoresis. All samples were diluted to a final concentration of $20 \mathrm{ng} / \mu \mathrm{l}$.

Thirty eight previously described by Reed and Rinehart (2007) SSRs primer sets were used. Their approach was modified and multiplex PCR assay was used instead of three-primer protocol providing visualizes only one SSR marker per reaction. For each primer set, forward primers were labeled with one of four fluorescent dyes: 6-FAM, ROX, R6G or TAMRA. Fluorescent dye selection was determined by the amplicon size. Primers amplified products with similar size were labelled with distinct dyes. A total of eight multiplexes were developed with 4-14 primer set for each. PCR reaction was made with the following components in the final volume of $25 \mu \mathrm{l}: 10 \mu \mathrm{l}$ 2.5-fold reaction mixture (Cat. No. M-428, Syntol, Russia) contained PCR buffer (KCl, TrisHCl (pH 8.8), $6.25 \mathrm{mM} \mathrm{MgCl}$ ), SynTaq DNA polymerase, dNTPs, 10 pmol each primer, $50 \mathrm{ng}$ genomic DNA. Fluorescence-labeled PCR was performed in a 2720 Thermal Cycler (Applied Biosystems) with an initial denaturation step at $95^{\circ} \mathrm{C}$ for $3 \mathrm{~min} ; 40$ cycles of $95^{\circ} \mathrm{C}$ for $40 \mathrm{sec}, 55^{\circ} \mathrm{C}$ for $40 \mathrm{sec}$, and $72^{\circ} \mathrm{C}$ for $1 \mathrm{~min}$; and one final cycle of $72^{\circ} \mathrm{C}$ for $5 \mathrm{~min}$. Amplicons were visualized by automated capillary gel electrophoresis on an ABI 3130xl (Applied Biosystems) using S-450 
size standard (Cat. No. MS-450, Syntol, Russia). Alleles were scored using the Soft Genetics Gene Marker software (Version 2.6.4). Data from all SSR loci were compiled for 39 samples and analyzed for shared allele frequencies. All alleles in this study were represented as diploid. Potential of locus was evaluated by allelic richness counting, allele frequencies and heterogeneity using PopGen32. Neighbor-joining method with 1000 bootstrap replicates for statistical support was used to generate a tree dendrogram. The dendrogram was generated with Darwin v.6.0 program.

Table 1. Hydrangea macrophylla cultivars used for genetic characterization with SSR markers.

\begin{tabular}{clcl}
\hline No. & Cultivar & No. & Cultivar \\
\hline 1 & Madame FaustinTravouillon & 21 & Hamburg-1 \\
2 & Madame de Vries & 22 & Hamburg- \\
3 & Madame Maurice Hamard-1 & 23 & Bouquet Rose \\
4 & Madame Maurice Hamard-2 & 24 & Popcorn \\
5 & Mariesii Silver-1 & 25 & 14494 \\
6 & MariesiiLilacina & 26 & Soeur Therese \\
7 & Mariesii Grandiflora & 27 & Joseph Banks \\
8 & Draps Wonder-1 & 28 & 14271 \\
9 & Draps Wonder-2 & 29 & Admiration-2 \\
10 & Le Cygne & 30 & Bichon \\
11 & Admiration-1 & 31 & Venus \\
12 & 12672 & 32 & 14573 \\
13 & BeauteVendomois & 33 & Selma \\
14 & Altona & 34 & Monsieur Ghys \\
15 & Mousseline & 35 & Jogosaki \\
16 & 13173 & 36 & Harlequin-2 \\
17 & Pensee & 37 & Alpenqluchen \\
18 & General Patton & 38 & MariesiiPerfecta \\
19 & GeneraleVicomtesse de Vibraye & 39 & MariesiiSilver-2 \\
20 & Harlequin-1 & & \\
\hline
\end{tabular}

\section{Results and Discussion}

SSR-bands or banding patterns that are unique to individual samples can be used for cultivar identification. In the present study only 36 of 38 SSR markers were visualized by automated capillary gel electrophoresis (Table 2). All of them were polymorphic and a total of 163 alleles were amplified. The largest number of alleles recovered from any SSR marker was eight with a mean value over all 36 loci recorded at 4.53 alleles per locus. Effective number of alleles varied from 1.08 (STAB107_108) to 4.24 (STAB421_422) with average of 2.36 for all loci. Nei's observed heterozygosity varied from 0.08 (STAB107_108 and STAB247_248) to 0.9 (STAB113_114), with an average of 0.54 across all loci. It means that about a half of loci are heterozygous. Polymorphic information content (PIC) values ranged from 0.071 (STAB107_108) to 0.73 (STAB421_422) with an average of 0.47 . The PIC value was more than 0.5 for 17 loci. So the SSR loci used were highly informative with sufficient discriminatory power to detect differences or similarities among genotypes. The Shannon diversity index (I) varied from 0.16 (STAB107_108) to 1.55 (STAB227_228), with an average of 0.97 across all loci. This indicates that this experimental group of cultivars has low diversity level. 
Table 2. Characteristics of 36 SSR loci used in the analysis of Hydrangea macrophyllla samples.

\begin{tabular}{|c|c|c|c|c|c|c|c|c|}
\hline $\begin{array}{l}\text { No. of } \\
\text { locus }\end{array}$ & Locus & Alleles & $\begin{array}{l}\text { Actual } \\
\text { allele size } \\
\text { range (bp) }\end{array}$ & $\begin{array}{l}\text { Effective } \\
\text { number of } \\
\text { alleles }\end{array}$ & I & PIC & $\mathrm{He}$ & Ho \\
\hline 1 & STAB061_062 & 2 & $103-106$ & 1.1655 & 0.2712 & 0.1319 & 0.1420 & 0.1538 \\
\hline 2 & STAB071_072 & 2 & $137-143$ & 1.4506 & 0.4896 & 0.2624 & 0.3107 & 0.3846 \\
\hline 3 & STAB091_092 & 6 & $158-179$ & 3.4647 & 1.4758 & 0.6757 & 0.7114 & 0.7436 \\
\hline 4 & STAB107_108 & 2 & $139-148$ & 1.0799 & 0.1630 & 0.0713 & 0.0740 & 0.0769 \\
\hline 5 & STAB113_114 & 4 & $112-121$ & 3.5413 & 1.3200 & 0.6659 & 0.7176 & 0.8974 \\
\hline 6 & STAB125_126 & 2 & $148-163$ & 1.1363 & 0.2381 & 0.1128 & 0.1200 & 0.1282 \\
\hline 7 & STAB137_137 & 6 & $121-148$ & 2.1228 & 1.0264 & 0.4788 & 0.5289 & 0.2821 \\
\hline 8 & STAB161_162 & 4 & $70-91$ & 2.0485 & 0.9704 & 0.4721 & 0.5118 & 0.4872 \\
\hline 9 & STAB165_166 & 4 & $150-159$ & 2.6429 & 1.0951 & 0.5559 & 0.6216 & 0.6667 \\
\hline 10 & STAB173_174 & 4 & 85-109 & 2.3673 & 1.0273 & 0.5094 & 0.5776 & 0.5385 \\
\hline 11 & STAB181_182 & 8 & $139-169$ & 3.5249 & 1.5354 & 0.6794 & 0.7163 & 0.7949 \\
\hline 12 & STAB193_194 & 4 & $127-155$ & 1.7905 & 0.8764 & 0.4149 & 0.4415 & 0.5385 \\
\hline 13 & STAB227_228 & 8 & $131-180$ & 3.4141 & 1.5522 & 0.6785 & 0.7071 & 0.8462 \\
\hline 14 & STAB239_240 & 6 & $154-169$ & 3.6962 & 1.4328 & 0.6824 & 0.7295 & 0.7949 \\
\hline 15 & STAB241_242 & 6 & $107-131$ & 3.6873 & 1.4631 & 0.6834 & 0.7288 & 0.6154 \\
\hline 16 & STAB247_248 & 4 & $118-127$ & 1.1098 & 0.2556 & 0.0972 & 0.0989 & 0.0769 \\
\hline 17 & STAB259_260 & 4 & $112-135$ & 2.3710 & 1.0229 & 0.5051 & 0.5782 & 0.5128 \\
\hline 18 & STAB271_272 & 2 & $134-137$ & 1.9677 & 0.6849 & 0.3709 & 0.4918 & 0.5128 \\
\hline 19 & STAB305_306 & 6 & $129-144$ & 3.6214 & 1.4110 & 0.6735 & 0.7239 & 0.8205 \\
\hline 20 & STAB317_318 & 3 & $144-153$ & 2.2286 & 0.9304 & 0.4864 & 0.5513 & 0.7436 \\
\hline 21 & STAB321_322 & 4 & $148-163$ & 1.9388 & 0.8859 & 0.4337 & 0.4842 & 0.6410 \\
\hline 22 & STAB347_348 & 5 & $145-169$ & 2.4752 & 1.1723 & 0.5553 & 0.5960 & 0.7949 \\
\hline 23 & STAB351_352 & 6 & $144-165$ & 1.7513 & 0.9321 & 0.4088 & 0.4290 & 0.2821 \\
\hline 24 & STAB363_364 & 5 & $85-103$ & 2.1901 & 1.0160 & 0.4836 & 0.5434 & 0.3846 \\
\hline 25 & STAB379_380 & 2 & $108-114$ & 1.8000 & 0.6365 & 0.3457 & 0.4444 & 0.5641 \\
\hline 26 & STAB389_390 & 5 & $84-96$ & 2.5329 & 1.1479 & 0.5480 & 0.6052 & 0.7692 \\
\hline 27 & STAB409_410 & 5 & $144-159$ & 1.9001 & 0.9625 & 0.4443 & 0.4737 & 0.3333 \\
\hline 28 & STAB421_422 & 5 & $135-150$ & 4.2427 & 1.5237 & 0.7274 & 0.7643 & 0.8462 \\
\hline 29 & STAB423_424 & 8 & $124-154$ & 2.5649 & 1.3319 & 0.5799 & 0.6101 & 0.5897 \\
\hline 30 & STAB429_430 & 2 & $87-90$ & 1.5505 & 0.5402 & 0.2920 & 0.3550 & 0.4103 \\
\hline 31 & STAB445_446 & 6 & $133-160$ & 1.5910 & 0.7907 & 0.3505 & 0.3715 & 0.3590 \\
\hline 32 & STAB501_502 & 2 & $97-106$ & 1.4175 & 0.4706 & 0.2512 & 0.2945 & 0.3077 \\
\hline 33 & STAB539_540 & 8 & $130-169$ & 2.9707 & 1.4559 & 0.6348 & 0.6634 & 0.6923 \\
\hline 34 & STAB567_568 & 3 & $148-161$ & 2.7040 & 1.0434 & 0.5563 & 0.6302 & 0.6923 \\
\hline 35 & STAB619_620 & 4 & $144-163$ & 1.7915 & 0.7715 & 0.3810 & 0.4418 & 0.5641 \\
\hline 36 & STAB647_648 & 6 & $107-143$ & 3.0852 & 1.3446 & 0.6307 & 0.6759 & 0.6410 \\
\hline \multicolumn{4}{|c|}{ Average } & 2.3594 & 0.9796 & 0.4675 & 0.5129 & 0.5413 \\
\hline
\end{tabular}

$\mathrm{I}=$ Shannon diversity index PIC $=$ Polymorphism information content; $\mathrm{He}=$ Expected heterozygosity; Ho = Observed heterozygosity. 
Total of 36 microsatellite loci were characterized for the allelic frequencies and heterogeneity level. Nine effective multiallelic markers with high level of heterozygosity (more than 0.7 ) and effective number of alleles (more than 3.5) were identified. This set of 9 markers (Table 2; locuses $5,11,13,14,15,19,28,33$ and 36) could be used for genotyping $H$. macrophylla cultivars. The dendrogram derived from allele sharing frequencies is presented in Fig. 1. Three major clusters were distinguishable, and two of these clusters included only mophead cultivars. The lacecap cultivars (underlined) clustered separately from the majority of mophead cultivars. The exception to this was Bichon and one of the Harlequin cultivars that were within the lacecap cluster.

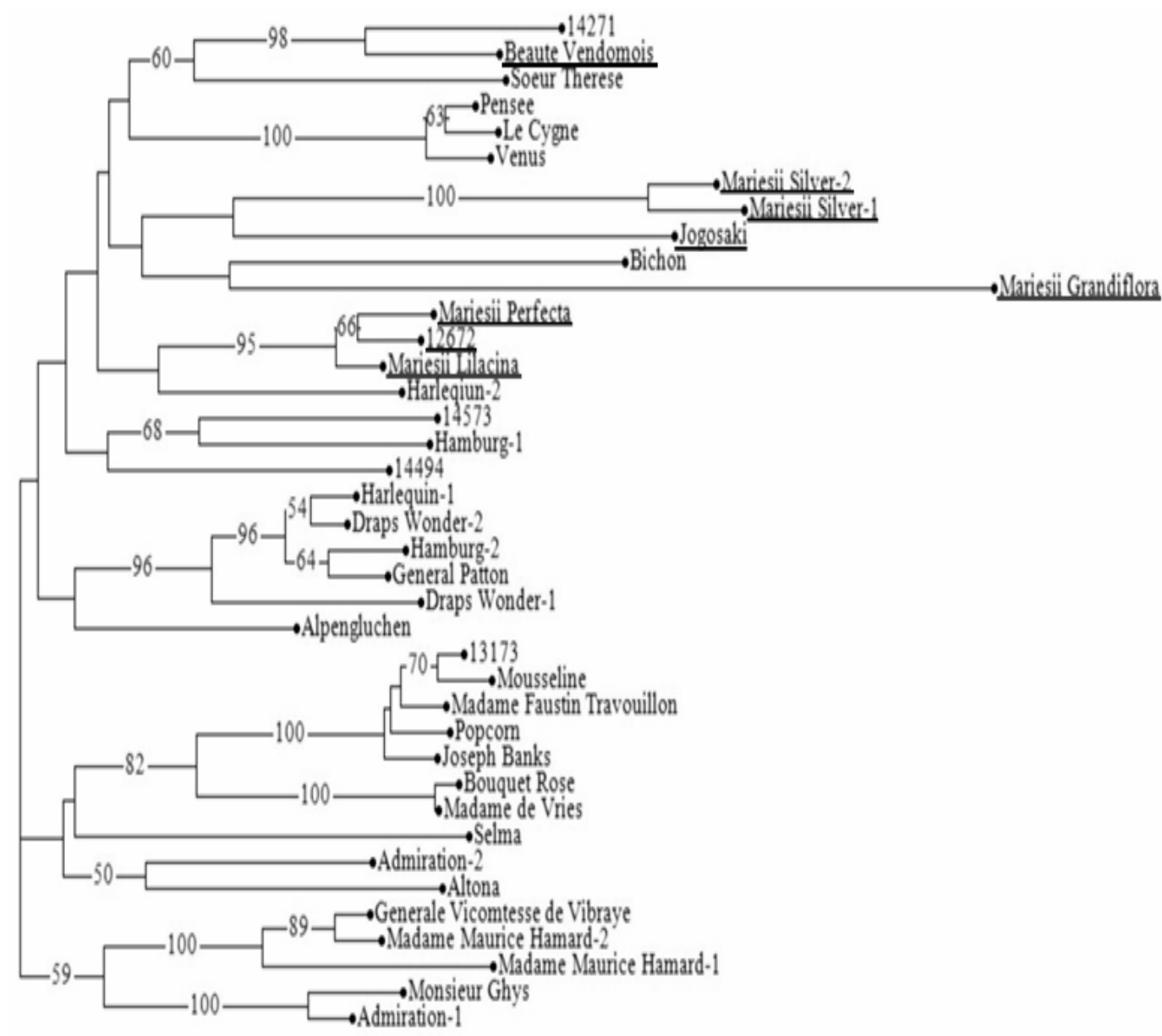

Fig. 1. Dendrogram of 39 Hydrangea macrophylla accessions based on Neighbor-Joining method. Numbers indicate bootstrap values (percentage of 1000 replicates). Bootstrap values greater than $50 \%$ are shown.

'Mariesii' was one of the first $H$. macrophylla cultivars imported to Europe from Asia in 1879. The French breeder Victor Lemoine selected cultivars of Mariesii series ('Mariesii Perfecta', 'Mariesii Lilacina', 'Mariesii Grandiflora', etc.) from an open-pollinated seedling population of 'Mariesii'. All cultivars from Mariesii series that were included in this study did not exhibit close genetic similarity to each other, suggesting none of these cultivars were full-sibs. Two samples of 'Mariesii Silver' introduced from different places, grouped together with 100\% bootstrap support. 
These two cultivars also have phenotypic similarities. This data confirms that these two samples are the same genotype, providing that one of them accumulated single random mutations that may occur in clonally propagated plants. 'Jogosaki' is also included in this grouping, which is particularly interesting because it was an old cultivar introduced from Japan to Europe, and possibly was used in the breeding of Mariesii series. 'Mariesii Grandiflora' located at a considerable distance from others. Although it falls in the same overall grouping with other Mariesii cultivars, 'Mariesii Grandiflora' showed no close genetic similarity to any other cultivar in this study.

Five of the cultivars included in this study were mislabeled. One of them, sample 14271 belonging to mophead group was introduced from China (Yunnan Province, Kunming City) to the Subtropical Botanical Garden in 2014. This shrub has double-flower, red sepals and its flowering periods from June to July. It grouped together with 'Beaute Vendomois' and 'Soeur Therese' samples. All these cultivars has large mophead (14271 and 'Soeur Therese') or lacecap ('Beaute Vendomois') inflorescences. 'Beaute Vendomois' has large flushed pale pink sepals, colorchanging to blue on acid soils with flowering time from July to September. 'Soeur Therese' flowered from June to August and had pure white inflorescence. Two examined samples 'Mariesii Perfecta', 'Mariesii Lilacina' of lacecap group showed close genetic similarity to each other and to the 12672 accession. The origin of 12672 is unknown. It started flowering from end of June to early August and color of sepals changed from white to dark pink when it is ageing. Sample 14494, which has introduced from Poland also changed color of sepals from white to dark pink, flowers from early June to the end of July. Sample 13173 started flowering in late spring to early summer and produced double-flower mophead inflorences. It exhibited genetic similarities to 'Mousseline' and 'Madame Faustin Travouillon'. Presumably this shrub was a branch spot of 'Madame Faustin Travouillon'.

Genetic similarities among two accessions of 'Madame Maurice Hamard' and one accession of 'Generale Vicomtesse de Vibraye' were also observed. These cultivars were developed by Emile Mouillère. 'Monsieur Ghys' also developed by Mouillèreis clustered near to this group. This data suggest that these cultivars have similar parentage. Analysis of two plants of 'Harlequin', 'Hamburg', 'Draps Wonder' and 'Admiration' cultivars received from different sources was carried out and the phenotypes of these cultivars are similar. However, there is no close genetic relationship between these. Reference accessions will be included in the further SSR-analysis of H. macrophylla for correct conclusions about cultivar labeling. 'Mariesii Perfecta', 'Mariesii Lilacina' (synonym, 'Lilicina') and 'Mariesii Grandiflora' (synonym, 'Whitewave') were selected from an open-pollinated seedling population of 'Mariesii'. It can be assumed that these cultivars were sibs. Previously reported study of Reed and Rinehart (2007) shows that these three cultivars have no close genetic similarity to each other and clustered separately. In the present study 'Mariesii Perfecta' and 'Mariesii Lilacina' cultivars clustered in one branch with 95\% bootstrap support, but 'Mariesii Grandiflora' also placed separately. In spite of previously published results, in the present study cultivars Mariesii Perfecta and Mousseline are placed in different clusters far away to each other. Also Mousseline and Joseph Banks cultivars grouped in one branch with $100 \%$ bootstrap support, that differs with previously reported data. Both in the study of Reed and Rinehart (2007) and in the present study 'Mariesii Grandiflora' and 'Beaute Vendomois' cultivars are placed in different branches of one cluster. 'Soeur Therese' and 'Beaute Vendomois' cultivars in the present study showed higher genetic similarity than in previously reported study $(60 \%$ bootstrap support).

Thirty six SSR markers were successfully used for analysis of relationships and genetic diversity among 39 accessions $H$. macrophylla collection for the first time in Russia. Nine SSR markers with clear polymorphism, high level of heterozygosity and effective number of alleles 
were found. Genetic structure of the Subtropical Botanical Garden collection was established. All accessions were grouped in three clusters, and lacecap cultivars clustered more closely to each other. These results will be useful in breeding programs and further genetic characterization of H. macrophylla.

\section{Acknowledgments}

This work was performed using the experimental climate control facility U-73547.

\section{References}

Adkins JA and DirrMA2003. Remontant flowering potential of ten Hydrangea macrophylla (Thunb.) Ser. cultivars. HortScience 38(7): 1337-1340.

Cerbah ME, Mortreau SB, Siljak-Yakovlev S, Bertrand H and Lambert C 2001. Genome size variation and species relationships in the genus Hydrangea. Theor. Appl. Genet. 103(1): 45-51.

Edwards K, Johnstone C and Thompson C 1991. A simple and rapid method for the preparation of plant genomic DNA for PCR analysis. Nucl. Acids Res. 19(6): 1349.

Jones KD, Reed SM and Rinehart TA 2006. Wide crosses in the Hydrangeaceae: Dichroafebrifuga $\times$ Hydrangea macrophylla. Proc. Southern Nursery Assn. Res. Conf. 51: 577-579.

Joung YH, Suh JK, Lee NS, Eum SM, Choi IY and Roh MS 2010. Identification of Hydrangeaceae accessions of wild origin from Jeju, Korea, using molecular markers. Plant Genetic Resources 8(03): 235-241.

Kardos JH, Robacker CD, Dirr MA and Rinehart TA 2009. Production and verification of Hydrangea macrophylla $\times$ H. angustipetala hybrids. Hort Science 44(6): 1534-1537.

Lee JH and Hyun JO 2007. The use of AFLP markers for cultivar identification in Hydrangea macrophylla. J. Korean Forestry Soc. 96(2): 125-130.

Lindstrom JT, Pelto MC and Dirr MA 2003. Molecular assessment of remontant (reblooming) Hydrangea macrophylla cultivars. J. Environ. Hort. 21(2): 57-60.

Malyarovskaya VI 2015. Variability of morphometric parameters in naturalized and cultivated Hydrangea macrophylla Ser. plants under different environmental conditions. Agr. Biol. 50(1): 92-98.

McClintock E 1957. A monograph of the genus Hydrangea. Proc. Calif. Acad. Sci. 29: 147-256.

Mortreau E, Bertrand H, Lambert C and Lallemand J 2003. Collection of Hydrangea: genetic resources characterization. Acta Hort. 623: 231-238.

Polyakova NV and Murzabulatova FK 2014.Method of estimation of decorative effect of Hydrangea L. Proceedings of the Samara Scientific Center of the Russian Academy of Sci. 16(1): 270.

Reed SM and Rinehart TA 2007. Simple sequence repeat marker analysis of genetic relationships within Hydrangea macrophylla. J. Amer. Soc. Hort. Sci. 132(3): 341-351.

Reed SM and Rinehart TA 2009. Simple-sequence repeat marker analysis of genetic relationships within Hydrangea paniculata. HortScience 44(1): 27-31.

Rinehart TA, Scheffler B and Reed SM 2005. Estimating genetic diversity within the Hydrangea genus using molecular markers. Sna Res. Conf. 50: 656-659.

Uemachi T, Mizuhara Y, Deguchi K, Shinjo Y, Kajino E and Ohba H 2014. Phylogenetic relationship of Hydrangea macrophylla (Thunb.) Ser. and H. serrata (Thunb.) Ser. evaluated using RAPD markers and plastid DNA sequences. J. Japanese Soc. Hort. Sci. 83(2): 163-171.

Van Huylenbroeck J, Eeckhaut T, Van Laere K and Van Bockstaele E 2004. Interspecific hybridization in woody ornamentals: how to deal with barriers? V International Symposium on In Vitro Culture and Hort. Breeding 725: 117-126.

(Manuscript received on 30 April, 2018; revised on 4 July, 2018) 